\title{
EPISTEMOLOGÍA APLICADA: METODOLOGÍA Y TÉCNICA DE LA PRODUCCIÓN CIENTÍFICA
}

\section{Héctor Maletta}

Lima, 2009. 419 p.

En el libro se presenta en cuatro partes los aspectos más relevantes de la ciencia y producción científica, la investigación científica, la argumentación científica y la comunicación científica.

En la primera parte, referida a la ciencia y la producción científica, se destaca los fundamentos de la producción científica, dentro de los cuales se desarrolla los aspectos más relevantes de : la producción, investigación y comunicación científica; explicando que la producción científica o académica, es el resultado de la investigación y comunicación científica. Así mismo, dentro de los fundamentos de la producción científica, describe y explica las características básicas de la labor científica y la delimitación de la actividad científica. Dentro de esta última, se describe y explica el positivismo, el falsicacionismo, los paradigmas y las revoluciones científicas, el pensamiento de Lackatos y la metodología de los programas científicos. Aquí, Lakatos, a partir de las ideas de Popper, desarrolla las denominadas hipótesis auxiliares operacionalizadas a través de los programas de investigación científica. También el autor, considera como fundamentos de la producción científica a las visiones críticas sobre la ciencia. Dentro de estas visiones críticas describe y explica: la ciencia juzgada por sus consecuencias, el anarquismo metodoló- gico, los cambios de paradigmas y relativismo epistemológico, la ciencia como construcción social, la ciencia como mera convención, la ciencia como retórica, el irracionalismo e intuición, el relativismo y escepticismo postmoderno, el dualismo epistemológico en las ciencias humanas y naturales, y el carácter contraintuitivo de la ciencia.

También el autor presenta en la primera parte, los componentes y fases de la producción científica. Aquí describe y explica como características generales de los componentes de la producción científi-

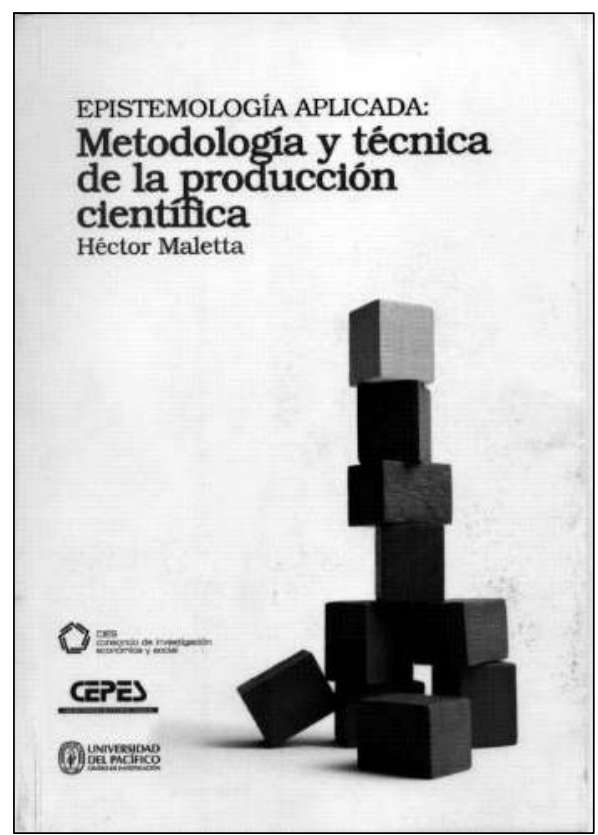


ca: el raciocinio y fundamento empírico, el naturalismo científico, el reduccionismo y las propiedades emergentes, el carácter social de la producción científica, el estudio e investigación, los niveles de investigación, los temas y problemas, y los problemas científicos y no científicos. Dentro de estos últimos: los problemas científicos y cotidianos, los problemas científicos y filosóficos, y los problemas científicos y sociales. Finalmente, en lo que se refiere a las características generales de los componentes de la producción científica, el autor describe y explica: las clases de problemas científicos, los programas, las áreas , los problemas y proyectos, y los resultados y productos.

En cuanto a las fases de la producción científica, el autor también describe y explica: las fases del proceso, las fases de un desarrollo tecnológico y el esquema general del proceso de producción científica.

Finalmente, en lo que respecta a los componentes y fases de la producción científica, se describe y explica: las ideas, los mapas conceptuales y los perfiles de productos de la producción científica.

En la segunda parte, denominada "Investigación científica", el autor describe y explica el proceso de investigación, la estrategia de investigación y la pesquisa bibliográfica.

En lo que respecta al proceso de investigación, destaca que es una fase o parte del proceso de producción científica. En lo que se refiere a la estrategia de investigación se describe y explica el diseño y estrategia, y dentro de este diseño y estrategias, destaca las investigaciones teóricas y empíricas, los diseños experimentales y no experimentales, los tipos de hipótesis y los diseños tecnológicos o de desarrollo. Así mismo, en lo que respecta a la estrategia de investigación, se hace referencia a la investigación cualitativa y cuantitativa, a la investigación exploratoria, a la delimitación de la investigación, al plan de trabajo y al proyecto como propuesta institucional.

En lo que se refiere a las pesquisas bibliográficas, se destaca que la producción científica implica una permanente labor de revisión bibliográfica, lo que conlleva al análisis del "estado del arte", teniendo en cuenta las técnicas para la pesquisa bibliográfica, la lectura y procesamiento de los materiales bibliográficos.

En la tercera parte, referida a la argumentación científica, el autor describe y explica: las bases de la argumentación científica y las falacias en el razonamiento científico. En lo referente a las bases de la argumentación científica enfatiza que los productos de la actividad científica se plasman usualmente en documentos expositivos, tales como: artículos, ponencias, tesis, propuestas o proyectos, libros, monografías, etc. Así mismo describe y explica: la lógica y argumentación, la estructura interna de una argumentación, los tipos de tesis, las argumentaciones, la evidencia probatoria y objeciones, y el desarrollo de la argumentación, En este último punto establece que es conveniente que haya en general una correspondencia entre la organización lógica de un producto científico, que se expresa en la articulación de argumentaciones de diferente nivel, y la organización expositiva, que se expresa en estructuras discursivas o textuales de diferente jerarquía.

En lo relacionado con las falacias en el 
razonamiento científico, establece que el estudio de las leyes de la lógica y de las reglas del correcto razonamiento científico permiten identificar falacias; es decir, vicios del razonamiento que conspiran contra la solidez de una argumentación. Así mismo, se establece las diferentes clasificaciones de falacias, tales como: clasificación de las falacias de Toulmin, Thompson, Dawnes y David Hacket Fisher. En estas última, el autor presenta en extenso la clasificación de las falacias de la investigación, donde destaca las siguientes: falacias de formulación de las preguntas o de las hipótesis, falacias en la corroboración empírica, falacias sobre la selección y significación de los hechos. También el autor establece las falacias de la explicación, destacando las siguientes: falacias de generalización, falacias de narración, falacias de causación, falacias de motivación, falacias de composición, falacias de analogía, falacias de distorsión semántica y falacias de distracción sustantiva.

En la cuarta y última parte, el autor hace referencia a la comunicación científica. Dentro de ella, describe y explica: el discurso expositivo científico, la estructura del texto expositivo y las estructuras subordinadas en el discurso expositivo

En cuanto al discurso científico, destaca el discurso expositivo en general. Aquí el autor establece que el discurso expositivo incluye no sólo a los textos científicos, sino también a otras clases de textos cuyo objetivo sea exponer un determinado asunto de manera ordenada y racional. En cambio, los discursos que no son expositivos son los poéticos, narrativos, epistolares, místicos, entre otros. Así mismo, describe y explica: las características de los escritos científicos, en donde destacan: el carácter expositivo, la argumentación racional, la rigurosidad teórica y metodológica, el valor agregado de originalidad, la unidad temática, la coherencia argumentativa, el respeto por las convenciones de la comunidad científica, el aparato bibliográfico, la audiencia profesional, el contenido relevante y el lenguaje adecuado.

En lo que se refiere al discurso expositivo en general, destaca los géneros de discurso científico, dentro de los cuales hace referencia a: los artículos, las reseñas, otros documentos científicos breves, las tesis, libros e informes técnico extensos. También, describe y explica: la producción de escritos científicos, las decisiones en la producción de escritos científicos, el alcance y contenido del producto escrito, la estrategia expositiva, la estructura jerárquica del discurso expositivo, y el esquema de contenido y su desarrollo.

En lo relacionado con la estructura del texto expositivo, el autor enfatiza las generalidades de dicha estructura, los elementos (palabras y oraciones), el párrafo en el discurso expositivo, las clases de párrafo expositivo, destacando los párrafos corroborativos, adversativos, definicionales, descriptivos, enumerativos y clasificatorios, comparativos y de síntesis. Así mismo, describe y explica: el desarrollo de los párrafos, los criterios para evaluar párrafos, cómo mejorar el impacto de un párrafo, el desarrollo de secciones y capítulos y el ordenamiento secuencial de los temas.

En cuanto a las estructuras subordinadas en el discurso expositivo, destaca la descripción y explicación del texto e hipertexto y el aparato bibliográfico. Den- 
tro de este último enfatiza en las fuentes y formatos, destacando el sistema autoraño, el sistema tradicional y el sistema de referencias numeradas. También incide en los aspectos del software bibliográfico, las transcripciones textuales, la lista de referencias bibliográficas. Dentro de estas últimas, se hace referencia a: autores y compiladores, al orden alfabético, los artículos, los libros y revistas, y otras clases de documento bibliográfico; así mismo, se menciona la editorial, lugar y fecha de publicación, la mención del volumen, el número y página, la bibliografía única o por temas, y las referencias internas o cruzadas. También, describe y explica sobre las notas y llamadas. Aquí destaca: las notas al pie y las notas al final, notas de referencia y notas de contenido, e inserción y numeración de notas. Así mismo se refiere a la presentación y contenido de cuadros, recuadros y gráficos; así como también, describe y explica las formas y el contenido de prefacios, prólogos e introducciones.

En cuanto a los elementos frontales y de presentación, el autor destaca: la cará- tula, tapa, portada o cubierta, información administrativa, dedicatoria, encabezamiento de un artículo, resumen (abstract), epígrafes, títulos y subtítulos.

También, describe y explica respecto a las tablas, listas e índices de la comunicación científica. Por ejemplo, hace referencia a las tablas de contenido, a la lista de cuadros, gráficos y otros elementos, lista de siglas y abreviaturas e índice analítico. Así mismo, se refiere a la numeración, destacando la numeración de páginas, la numeración de capítulos y secciones, numeración de cuadros, ecuaciones y gráficos.

Finalmente, el autor describe y explica los materiales ampliatorios, como por ejemplo, la addenda, los anexos y apéndices, así como la estructura general de una tesis y de un libro científico.

Mg. Econ. Fernando Vásquez Pacheco

Magister en Ciencias de la Educación Superior. Magister en Contabilidad, Mención: Docencia Universitaria e Investigación. Docente Investigador de la Carrera Profesional de Derecho. Jefe del Departamento Académico de Metodología de la Investigación. 